\title{
Language Learning Strategies Using on Vocabulary Learning
}

\author{
Ching-Ying Lin*, Si-Wei Hong \\ Department of applied English, National Pingtung University, Taiwan
}

*Corresponding Author: Ching-Ying Lin, Department of applied English, National Pingtung University, Taiwan

\begin{abstract}
Language learning strategies are recognized as the way that people learn language easily and effectively. However, they are affected by different factors. This study use questionnaire based on Oxford's (1990) Strategy Inventory for Language Learning Strategies (SILL) and Schmitt's (1997) Taxonomy of Vocabulary learning strategies with five-point Likert-scale to detect the general language learning strategies used by thirty- two Taiwanese students, and also detect language learning strategies used by different gender and ages. The result showed that Taiwanese English learners do not apply language learning strategies on language learning frequently. Determination strategies are frequently used by students, metacognitive strategies are less used. The study found no significant difference between different genders of learners but female is more frequently used than male. The adult learners was detected that they are the most frequently used language learning strategies of all school levels.
\end{abstract}

Keywords: Language Learning Strategy; Vocabulary Learning Strategy; ESL Learners; Gender Difference; Age Difference

\section{INTRODUCTION}

Language learning strategies were received more attention from researchers for many years. Oxford (1990) claimed that learners enhance their learning by using language learning strategies. In other words, application of language learning strategies assists learners to learn language more effectively. Therefore, Language learning strategies play a principal role in language learning. Recognizing, comprehending, and using vocabulary is a necessary aspect in learning English. (Ak Sedau, 2004). Learning vocabulary with different strategies caused different vocabulary knowledge. Schmitt (2004) indicated that the four language skills can be sorted into two parts: receptive and expressive (productive) knowledge competence. He claims that" receptive knowledge competence regard to both listening and reading skills, while productive knowledge competence is concerned about speaking and writing skills."(p.4) with adequate vocabulary knowledge, learners can comprehend the contexts in the materials, express their own ideas and stimulate their learning motivation.

Oxford (1990) indicated individual differences affect choice of language learning strategies. Learners who come from diverse background have different gender, age, personality, learning style, background knowledge, language proficiency, and learning motivation.

Learning English as second language is necessary issue in Taiwan for the recent years. Comrie and Corbett (2009) indicated when learners' first language and second language are similar symbol system and pattern, it will make learner easily acquire. There is a different language system and pattern between Chinese and English. Therefore, it causes some problems on learning English for Chinese learners.

Moreover, a lot of researches were investigated learners' language learning on language learning strategies, however, language learning strategies affect by gender differences and different ages did not receive much attention in the past literature.

Therefore, the purpose of the study was explored students' language learning strategies used, investigated what similar and different vocabulary learning strategies might be used by male and female, and detected English learners' language learning strategies use at different ages. Hence, learners have a deeper understand of language learning strategies use, and they achieve learning goal with appropriate strategies. According to the reason, the following questions were draw:

- What kinds of language learning strategies do learners use on vocabulary learning? 
- Are there gender differences in using language learning strategies on vocabulary learning?

- Are there differences in using language learning strategies on vocabulary learning by different age of learners?

\section{LITERATURE REVIEW}

\subsection{Language Learning Strategies}

Strategies are tools that lead a best way for language learning. Oxford (1990) detect that learning strategies functions to engage learners to acquire, store, retrieve, and use information. Therefore, Oxford (1990) state that using the appropriate strategies leads to learn language more easy, rapidly, enjoyably, effectively, and advance language proficiency and achievement in language four skills( listening, speaking, reading, writing). Students with language learning strategies used develop independent, self-directed, automatic learning. They apply strategies to arrange personal learning plans, achieve their goals and gain greater self-confidence in language learning. The main goal of language learning intends to communication competence. In other words, learners learn how to apply English to communicate in different situations and share their ideas with others by developing communication competence as the main purpose for language learning. $=$

\subsubsection{Taxonomy of Language Learning Strategies}

According to Oxford (1990), learning language strategies are sort into two major classes, direct and indirect. Direct language learning strategies for dealing with the target language itself; indirect language learning strategies for management of language. These two classes are classifying into six groups (three groups for each class).

Direct language learning strategies are subdivided into memory strategies, cognitive strategies, and compensation strategies. Memory strategies assist learners to remember and retrieve new information about new language, such as grouping, associating, physical action; cognitive strategies facilitate learners to realization and production of new target language by different means, such as repeating, practicing, analyzing, taking notes; compensation strategies allow learners to utilize the language despite restriction of knowledge, such as using clue, translating to mother tongue, using gesture.

Indirect language learning strategies are composed of metacognitive strategies, affective strategies, and social strategies. Metacognitive strategies support learners to coordinate learning process, such as planning, organizing, setting goals, evaluating.; affective strategies assist learners to control emotion and attitude, such as lowing anxiety, encouraging, rewarding.; and social strategies facilitate learners to learn with others by interaction, cooperation, such as asking questions, cooperating with others.

\subsection{Language Learning Strategies on Vocabulary Learning}

Vocabulary is an essential aspect in language learning. However, second language learners are usually regard vocabulary learning as a hard task. With adequate vocabulary knowledge, learners are able to comprehend content in different reading materials, express their own ideas, and communicate with others.

According to Schmitt (1997), vocabulary learning strategies was organized on the basic of Oxford's (1990) language learning strategies and Discovery/ Consolidation distinction. According to Schmitt (1997), vocabulary learning strategies are divided into five groups; include determination strategies, social strategies, memory strategies, cognitive strategies, and metacognitive strategies.

Determination strategies aid learners to obtain meaning and knowledge of unknown words, such as analyzing part of speech, guessing from context, using dictionary; social strategies assist learners to cooperate with others, such as asking teachers or peers for meaning of new word, interacting with native speakers; memory strategies use imagination, previous knowledge to gain meaning of words, such as association, pictorial representation, physical action; cognitive strategies facilitate learners learn vocabulary through repetition, take note, physical objects, such as verbal and written repetition, flash cards, word lists; and metacognitive strategies are used to control and evaluate learners' leaning, such as testing, skipping, skimming, reviewing.

\subsection{The Effects of Gender}

Oxford (1990) stated that many factors impact on strategies choice. One of the factors is gender. 
Many research probed that females use strategies in learning more than males. However, some research indicated that males use more learning strategies than females. Even, a few of research reported that no significant difference between male and female on language learning strategies use.

In Aliakbari's and Hayatzadeh's (2008) research, 50 learners at university who are 19 males and 31 females in Iran probed that male use language learning strategies more frequently than female. To be specific, male learners indicate that they use metacognitive strategies most frequently than other strategies in language learning. In Lee's (2010) research, 250 learners (50 males and 200 females) at university probed that males use more strategies in language learning than females, especially, cognitive and compensation strategies.

Malik and Akhtar (2015) conducted 3026 learners at college school who were 1475 males and 1551 females, the finding showed that females use metacognitive strategies more frequently than males; however, males use cognitive strategies more than females. In Zeynali's (2012) research with 149 learners who are 46 males and 103 females at junior high school to university (15 to 32 years old). It probed that females tend to use more learning strategies than males, moreover, use social and affective strategies more than males. In other words, females tend to be aware of their feelings on language learning. According to Alhaysony's (2017) research, there were 66 males and 68 female participate in, it showed that females use language learning strategies more frequently than males. In Ahour's and Abdi's (2015) research, they conducted they study with 150 learners were 75 males and 75 females, they reported that females use language learning strategies more than males. Wu (2014) reported 100 learners who were 47 males and 53 females were reported females use strategies in language learning more than males. In Huang's (2015) research, the participants are 322 college learners (155 males and 167 females). It indicated female use metacognitive strategies more frequently than male.

Marzban and Barati (2016) investigated 79 learners of college school in Iran who were 31 males and 48 males, the result reported there is no significant difference of language learning strategies use on gender effect. Huang (2017) probed that there is no significant difference between male and female with 333 senior high school learners (165 males and 168 female).

\subsection{The Differences on Different School Levels}

Learners at different school levels are one of the factors that influence on language learning strategies choice. Oxford (1990) indicated that older or advanced learners tend to apply different strategies in language learning completely than younger or primary learners. Learners have different cognitions thought growing stages. Because of different degree of cognition, choosing strategies for language learning were varied. Learners who are in different school level (elementary, junior high school, senior high school and university) must to choose appropriate learning strategies to study vocabulary effectively. Such as learners at elementary level should employ visual aid assist them to comprehend the meaning of words. However, learners at elementary level use guessing from context, they probably can't receive the accurately meaning of words, because of insufficient background knowledge.

100 learners at elementary school were conducted in Wu's (2014) research, they use cognitive strategies in language learning most frequently, and however, the least frequently used is affective and social strategies. In Hsiung's (2011) research, the participants are 64 junior high learners in Taiwan who reported the most frequently used strategies is determination strategies, and the less frequently use is social strategies.

According to Ahour and Abdi (2015), 150 learners at senior high school to university (18-25 years old) indicated that the most frequently used strategies is memory strategies, the least frequently used strategies is social strategies. Huang (2017) reported that the 333 senior high school learners who use compensation strategies most frequently in language learning, and memory strategies is least frequently use.

According to Aliakbari and Hayatzadeh (2008), 50 learners at university who learn English as a foreign language in Iran reported that metacognitive strategies are most frequently used for them to learn English. It perhaps they are aware of planning, organizing, and evaluating learning as an important step on language learning. In Alhaysony's (2017) research, 134 learners major in English at university were enrolled in this study. The finding reported the most frequently use cognitive strategies on language learning and the second is metacognitive strategies. In Chuin's and Kaur's 
(2015) research, 73 learners at university who reported that metacognitive strategies are the most frequently used, affective strategies are the least frequently used. Lee (2010) reported that 250 learners at university who use most frequently strategies is compensation strategies, in contrast, the least frequently used strategies is memory strategies.

In Chen (2014) research, 249 elementary school learners (10 to 12 years old) indicated that they use metacognitive strategies more frequently than others, and the least use compensation strategies; 245 junior high school learners (13 to 15 years old) who reported that compensation strategies is the most frequently use in language learning, the less frequently use affective strategies; 249 senior high school learners (16 to 18 years old) also reported the same result; 279 university learners (20 to 22 years old) were detected the most frequently used strategies is compensation strategies, memory strategies is the least frequently used than other strategies. The research probed learner at high education levels prefer to use compensation strategies than learners at elementary school.

According to Sepasdar's and Soori's (2014) research, 24 elementary school learners (age 10 to 12) were detected the most frequently used strategies is metacognitive strategies, compensation strategies is the least frequently used than other strategies; 23 junior high school learners (age 13 to 15) indicated that they use compensation strategies more frequently than other strategies, and the least use affective strategies; 25 senior high school learners (age 16 to 18) also reported the same result as junior high school learners indicated; 22 university learners (age 19 to 23) who reported that compensation strategies is the most frequently use in language learning, the less frequently use memory strategies.

\subsubsection{Summary}

Elementary school learners have insufficient knowledge background to support them use this strategies. Because of insufficient knowledge background, learners at elementary school tend to use memory strategies to receipt information through images and sound. On the other hand, learners of high education levels use social and affective strategies more frequently than learners of low levels education on language learning. Learners at high levels education engage in social activities to communicate with others, cooperate with peers to enhance their production skill.

\section{Methodology}

This study aimed to examine language learning strategies use, also to compare language learning strategies use by the effect of gender and different school levels. This study uses a questionnaire to collect data.

\subsection{Participants}

The 32 participants were junior school, senior high school students and adults in Taiwan. They learn English as a second language. There were 15 males and 17 females in the study. The different ages of learners are 13 junior high school (between 13-15 years old.), 14 senior high school (between 16-18 years old) and 5 adults (over 23).

\subsection{Instruments}

The questionnaire developed by Hsiung (2011) was used in the present study. Part I used to detect students' background information includes gender (male and female) and school levels (elementary school, junior high school, and senior high school). Part II is items about language learning strategies on vocabulary learning. The questionnaires were 60 items based on both Oxford's (1990) Strategy Inventory for Language Learning Strategies (SILL) and Schmitt's (1997) Taxonomy of Vocabulary learning strategies with five-point Likert-scale. (always or almost always true of me - 5 point, usually true of me -4 point, somewhat true of me -3 point, usually not true of me -2 point and never or almost never true of me -1 point). This 60 items organized into six different types of language learning strategies: determination strategies (questions 1 to 7), memory strategies (question 8 to 26), cognitive strategies (question 27 to 35), metacognitive strategies (question 36 to 44), affective strategies (questions 45 to 54), and social strategies (questions 55 to 60).

\subsection{Data Collection Procedures}

The researcher obtains the acceptation to get in the classes from the teachers, also arrange the dates of visit. On arranged date, the researcher goes to the each class at junior high school, senior high school, and cram school. After get in the class, the research illustrates the purpose of the questionnaire, moreover, 
asked learners to reply each question honestly and anonymously. When finished the questionnaire, the researcher confirms all of the questionnaire were collected and every items were completed.

\subsection{Data Analyses}

The data from the questionnaire were analyzed quantitatively. To probe students' perceptions of language learning strategies, the descriptive statistics of means, frequencies, and percentages were reported. To explore the similarities and differences between males' and females' learners' perceptions in language learning strategies, independent t-tests were conducted. To detect language learning strategies use by different ages of learners, the one way ANOVA were conducted. To be specific, the Tukey's HSD used to detect the significant difference which group significantly differs from which one. When samples are not equal, the variance is not homogeneity; it has to go on Tamhane.

\section{RESULT}

The results in this study are extended to the three research questions. General language learning strategies used on vocabulary learning are presented first. Second, the effects of gender difference in overall language learning strategies and special strategies on vocabulary learning used are addressed. Differences in language learning strategies used on vocabulary learning are addressed according to different school levels.

\subsection{Results of Language Learning Strategies on Vocabulary Learning}

The Mean of the overall language learning strategies used on vocabulary learning are 3.28. Determination strategies were used most frequently (Mean=3.81, $\mathrm{SD}=0.99)$, metacognitive strategies (Mean=3.01, $\mathrm{SD}=1.18$ ) were least frequently used.

To be specific into 60 items, the most frequently used language learning strategies on vocabulary learning were found in the item of I guess from picture, word cards or action. (Mean=4.47, SD=.567) The second frequently used language learning strategies on vocabulary learning were detected in the items of I use music to relax. (Mean=4.41, SD=.875). The third frequently used language learning strategies on vocabulary learning were detected in the items of I look up word in electronic or online dictionary. (Mean=4.28, SD=1.054). The forth frequently used language learning strategies on vocabulary learning were found in the items of I use verbal repetition. (Mean=4.25.SD=.718). The fifth frequently used language learning strategies on vocabulary learning were detected in the item of I take notes in class. (Mean=4.22, SD=.87) (See Table1)

Table1. Top Five Most Frequently Used Language Learning Strategies on Vocabulary Learning

\begin{tabular}{|l|l|l|c|}
\hline Rank & \multicolumn{1}{|c|}{ Items } & Mean & SD \\
\hline 1 & I guess from picture, word cards or action. (determination strategy) & 4.47 & 0.567 \\
\hline 2 & I use music to relax. (affective strategy) & 4.41 & 0.875 \\
\hline 3 & I look up word in electronic or online dictionary. (determination strategy) & 4.28 & 1.054 \\
\hline 4 & I use verbal repetition. (cognitive strategy) & 4.25 & 0.718 \\
\hline 5 & I take notes in class. (cognitive strategy) & 4.22 & 0.870 \\
\hline
\end{tabular}

The first least frequently used language learning strategies on vocabulary learning were found in the items of I put English labels on physical objects. (Mean=1.78, SD=1.157). The second least frequently used language learning strategies on vocabulary learning were found in the items of I write a language learning diary. (Mean=2.03, $\mathrm{SD}=1.15)$. The third least frequently used language learning strategies on vocabulary learning were found in the items of I use a checklist. (Mean=2.22, SD=.975). The forth least frequently used language learning strategies on vocabulary learning were found in the items of I use Keyword Methods. (Mean= 2.44, SD=1.268). The fifth least frequently used language learning strategies on vocabulary learning were detected in both items of I use flesh card (Mean=2.53, $\mathrm{SD}=.983$ ) and I listen to English broadcast (Mean=2.53, $\mathrm{SD}=1.191$ ), as indicated in Table2.

Table2. Top Five Least Frequently Used Language Learning Strategies on Vocabulary Learning

\begin{tabular}{|l|l|l|l|}
\hline \multicolumn{1}{|c|}{ Rank } & \multicolumn{1}{|c|}{ Items } & \multicolumn{1}{c|}{ Mean } & \multicolumn{1}{c|}{ SD } \\
\hline 1 & I put English labels on physical objects. (cognitive strategy) & 1.78 & 1.157 \\
\hline 2 & I write a language learning diary. (affective strategy) & 2.03 & 1.150 \\
\hline 3 & I use a checklist. (affective strategy) & 2.22 & 0.975 \\
\hline 4 & I use Keyword Methods. (memory strategy) & 2.44 & 1.268 \\
\hline
\end{tabular}




\begin{tabular}{|l|l|l|l|}
\hline 5 & I use flesh card. (cognitive strategy) & 2.53 & 0.983 \\
\hline 6 & I listen to English broadcast. (metacognitive strategy) & 2.53 & 1.191 \\
\hline
\end{tabular}

\subsection{Results of Language Learning Strategies on Vocabulary Learning Used by Different Gender}

The $t$-value of the overall language learning strategies use on vocabulary learning by different gender is -0.6 at p-value is 0.54 , it shows no significance differences between two different genders. But the Mean of language learning strategies on vocabulary learning used by female learners is higher than male learners in six different types of strategies, as indicated in Table3.

Table3. Independent $t$ Tests on Type of Language Learning Strategies on Vocabulary Learning Used by Male and Female Learners

\begin{tabular}{|c|c|c|c|c|c|}
\hline Type & Learners & Mean & SD & $\mathbf{T}$ & $\mathbf{P}$ \\
\hline \multirow{2}{*}{ Determination Strategies } & Male & 3.59 & 1.06 & \multirow{2}{*}{-1.1} & \multirow{2}{*}{0.50} \\
\hline & Female & 4.01 & 0.88 & & \\
\hline \multirow{2}{*}{ Memory Strategies } & Male & 3.03 & 1.23 & \multirow{2}{*}{-0.59} & \multirow{2}{*}{0.46} \\
\hline & Female & 3.28 & 0.97 & & \\
\hline \multirow{2}{*}{ Cognitive Strategies } & Male & 3.12 & 1.05 & \multirow{2}{*}{-0.39} & \multirow{2}{*}{0.61} \\
\hline & Female & 3.28 & 0.1 & & \\
\hline \multirow{2}{*}{ Metacognitive Strategies } & Male & 2.93 & 1.31 & \multirow{2}{*}{-0.38} & \multirow{2}{*}{0.61} \\
\hline & Female & 3.07 & 1.09 & & \\
\hline \multirow{2}{*}{ Affective Strategies } & Male & 3.01 & 1.2 & \multirow{2}{*}{-0.64} & \multirow{2}{*}{0.54} \\
\hline & Female & 3.31 & 1.13 & & \\
\hline \multirow{2}{*}{ Social Strategies } & Male & 3.21 & 1.04 & \multirow{2}{*}{-0.52} & \multirow{2}{*}{0.5} \\
\hline & Female & 3.40 & 1.08 & & \\
\hline \multirow{2}{*}{ Overall } & Male & 3.15 & 1.15 & \multirow{2}{*}{-0.60} & \multirow{2}{*}{0.54} \\
\hline & Female & 3.39 & 0.88 & & \\
\hline
\end{tabular}

In closer to 60 language learning strategies on vocabulary learning items use by different genders of learners, the t-value is-2.12 at p-value is .043 was found in items of I look up words in bilingual dictionary (paper). In the item of I discover the meaning of a new word through group work activities was found significant difference with the $\mathrm{t}$-value is-2.19 at p-value is .036 . The $\mathrm{t}$-value is-2.52 at $\mathrm{p}$ value is .021 was found in items of I underline initial letter of the word; it is shows significance differences between two difference genders of learners. (See in Table4).

Table4. Significant for Independent $t$ Tests on Individual Items of Female and Male Learners' Language Learning Strategies on Vocabulary Learning Used

\begin{tabular}{|c|c|c|c|c|c|}
\hline Items & Learners & Mean & SD & $\mathbf{T}$ & $\mathbf{P}$ \\
\hline \multirow{2}{*}{ I look up words in bilingual dictionary (paper). } & Male & 2.73 & 1.03 & \multirow{2}{*}{-2.12} & \multirow{2}{*}{.043} \\
\hline & female & 3.59 & 1.23 & & \\
\hline \multirow{2}{*}{$\begin{array}{l}\text { I discover the meaning of a new word through group } \\
\text { work activities. }\end{array}$} & Male & 2.40 & 0.91 & \multirow{2}{*}{-2.19} & \multirow{2}{*}{.036} \\
\hline & female & 3.24 & 1.2 & & \\
\hline \multirow{2}{*}{ I underline initial letter of the word. } & Male & 3.20 & 1.37 & \multirow{2}{*}{-2.52} & \multirow{2}{*}{.021} \\
\hline & female & 4.18 & 0.64 & & \\
\hline
\end{tabular}

\subsection{Results of Language Learning Strategies on Vocabulary Learning Used by Different Ages}

The F-value of the overall language learning strategies use on vocabulary learning by different ages is 1.367. The Mean of language learning strategies on vocabulary learning used by adult learners is highest of all different school levels in six different types of strategies, as indicated in Table5.

Table5. One-way ANOVA on Type of Language Learning Strategies on Vocabulary Learning Used by Different Ages of Learners

\begin{tabular}{|c|c|c|c|c|}
\hline Type & Learners & Mean & SD & $\mathbf{F}$ \\
\hline \multirow{3}{*}{ Determination Strategies } & Junior & 3.61 & 1.03 & \multirow{3}{*}{1.4} \\
\hline & Senior & 3.95 & 0.98 & \\
\hline & Adult & 3.86 & 0.67 & \\
\hline \multirow{2}{*}{ Memory Strategies } & Junior & 3.05 & 1.25 & \multirow{2}{*}{1.16} \\
\hline & Senior & 3.13 & 1.06 & \\
\hline
\end{tabular}




\begin{tabular}{|c|c|c|c|c|}
\hline & Adult & 3.45 & 0.73 & \\
\hline \multirow{3}{*}{ Cognitive Strategies } & Junior & 2.9 & 1.07 & \multirow{3}{*}{2.52} \\
\hline & Senior & 3.2 & .87 & \\
\hline & Adult & 3.84 & .81 & \\
\hline \multirow{3}{*}{ Metacognitive Strategies } & Junior & 2.81 & 1.39 & \multirow{3}{*}{0.68} \\
\hline & Senior & 2.98 & 1.05 & \\
\hline & Adult & 3.4 & 0.84 & \\
\hline \multirow{3}{*}{ Affective Strategies } & Junior & 2.9 & 1.15 & \multirow{3}{*}{1.16} \\
\hline & Senior & 3.15 & 1021 & \\
\hline & Adult & 3.7 & .76 & \\
\hline \multirow{3}{*}{ Social Strategies } & Junior & 3.1 & 1.03 & \multirow{3}{*}{1.28} \\
\hline & Senior & 3.32 & 1.13 & \\
\hline & Adult & 3.83 & 0.91 & \\
\hline \multirow{3}{*}{ Overall } & Junior & 3.06 & 1.15 & \multirow{3}{*}{1.367} \\
\hline & Senior & 3.29 & 1.05 & \\
\hline & Adult & 3.68 & 0.79 & \\
\hline
\end{tabular}

The variance is homogeneity, so we go on Tukey HSD. To be specific, 60 language learning strategies on vocabulary learning items use by different ages of learners. The result of Tukey HSD shows that the item of I put English labels on physical objects between junior learners and adult learners with $\mathrm{MD}$ is -1.55 at $\mathrm{p}$-value is .029 ; The item of I keep new word on a vocabulary notebook between junior learners and adult learners with MD is -1.83 at $\mathrm{p}$-value is .01 ; also this method between senior learners and adult learners with MD is -1.5 at p-value is .034; Between junior learners and adult learners with MD is -1.95 at p-value is .038 was found in items of I discover the meaning of a new word through group work activities. All of them show significances. (See in Table6).

Table6. Significant for Tukey HSD on Individual Items of Different Ages of Learners' Language Learning Strategies on Vocabulary Learning Used

\begin{tabular}{|l|l|l|l|c|}
\hline \multicolumn{1}{|c|}{ Items } & Level 1 & Levels & \multicolumn{1}{c|}{ Md } & P \\
\hline I put English labels on physical objects. & junior & adult & $-1.55^{*}$ & .029 \\
\hline \multirow{2}{*}{ I keep new word on a vocabulary notebook. } & junior & adult & $-1.83^{*}$ & .01 \\
\cline { 2 - 5 } & senior & adult & $-1.50^{*}$ & .034 \\
\hline I discover the meaning of a new word through group work activities. & junior & adult & $-1.95^{*}$ & .038 \\
\hline
\end{tabular}

The variance is not homogeneity, so we go on Tamhane test. The result of Tamhane shows that the item of I guess from pictures, word card or actions between junior learners and adult learners with MD is .58 at p-value is .007; also this method between senior learners and adult learners with MD is .50 at p-value is .038 ; The item of I look up word in electronic or online dictionary between junior learners and adult learners with MD is -1.08 at p-value is .046 ; Between junior learners and adult learners with MD is -.83 at p-value is .031 was found in items of I use music to relax. All of them show significances. (See in Table7).

Table7. Significant for Tamhane Test on Individual Items of Different Ages of Learners' Language Learning Strategies on Vocabulary Learning Used

\begin{tabular}{|l|l|l|l|l|}
\hline \multicolumn{1}{|c|}{ Items } & \multicolumn{1}{|c|}{ Level 1 } & \multicolumn{1}{c|}{ Levels } & \multicolumn{1}{c|}{ Md } & P \\
\hline \multirow{2}{*}{ I guess from pictures, word card or actions. } & junior & adult & $.58^{*}$ & .007 \\
\cline { 2 - 5 } & senior & adult & $.50^{*}$ & .038 \\
\hline I look up word in electronic or online dictionary. & junior & adult & $-1.08^{*}$ & .046 \\
\hline I use music to relax. & junior & adult & $-.83^{*}$ & .031 \\
\hline
\end{tabular}

\section{CONCLUSION}

According to the result of the study, Taiwanese English learners do not often use language learning strategies to learn vocabulary. Determination strategies are highest frequently language learning strategies used by the learners; metacognitive strategies was used lowest frequently language learning strategies. Oxford (1990) state that using the appropriate strategies leads to learn language more easy and advance language proficiency and achievement in language four skills. Moreover, metacognitive strategies support learners to coordinate learning process; Language learning requires long-term use to maintain. In Taiwan, English learner should use appropriate to assist them studying language. 
The present study also found no significant difference between two different genders of learners in overall of language learning strategies used. But the Mean of language learning strategies used by female learners is higher than language learning strategies used by male learners in six different types of strategies.

In addition, the Mean of language learning strategies on vocabulary learning used by adult learners is highest of all school levels in six different types of strategies. Learners have different cognitions thought growing stages. Because of different degree of cognition, choosing strategies for language learning were varied. Junior and senior learners may use fewer strategies to language learning according their educational need than adult learners.

\section{REFERENCE}

[1] Oxford, R. L. (1990). Language Learning Strategies: what every teacher should know. In R.L. Oxford (Eds.)

[2] Ak Sedau, E. (2004). Exploring Vocabulary Difficulty in English Literature Classroom and Solutions: an Action Research. Retrieved on November 24, 2016 from http://ir.unimas.my/3441/1/Exploring\%20 vocabulary\%20difficulty\%20in\%20english\%20literature\%20classroom\%20and\%20solutions $\% 20$ an $\% 20$ ac tion\%20research.pdf

[3] Schmitt, N. (2004). Vocabulary in language teaching. 4th ed. Cambridge: Cambridge University Press. Retrieved on April 19, 2017 from http://catdir.loc.gov/catdir/samples/cam032/99057110.pdf

[4] Comrie, B. \& Corbett, G. (2009). Crosslinguistic influences. In B. Comrie \& G.Corbett (Eds.), understanding Second language acquisition (pp. 31-54). Lourdes Ortega.

[5] Schmitt, N. (1997). Vocabulary learning strategies. In N. Schmitt \& M. Mccarthy (Eds.), Vocabulary: Description, Acquisition and Pedagogy. Cambridge University Press. Retrieved on April 19, 2017 from http://r.search.yahoo.com/_ylt=AwrsAXDCPAdZXPwArcmX2At.;_ylu=X3oDMTBydTdmYjgyBHNIYw NzcgRwb3MDMQRjb2xvA3R3MQR2dGlkAw--/RV=2/RE=1493675330/RO=10/RU=http\%3a\%2f\%2 fwww.norbertschmitt.co.uk\%2fuploads\%2fschmitt-n-\%281997\%29-vocabulary-learning-strategies-in schmitt-nand-mccarthy-m-\%28eds\%29-vocabulary-description-acquisition-and-pedagogycambridgeuniversity-press.doc/RK=0/RS=w1tO2c52UolOSw7OkpKTqnH3crw-

[6] Aliakbari, M. \& Hayatzadeh, A. (2008). Variation of Language Strategies Among Iranian English Students: The Effect of Gender. International Journal of Pedagogies and Learning. 4(3), 72-87.

[7] Lee, J.J. (2010). Learning Strategies Associated With Gender Differences and Strategy Choices: A Study of Taiwanese Students in English Medium Programs. Unpublished Master's Thesis, Ming Chuan University, Taiwan.

[8] Malik, I. H. \& Akhtar, M. (2015). Difference in the Use of English Vocabulary Learning Strategies at Higher Secondary Level. Journal of Educational Research, 18(1), 96-105.

[9] Zeynali, S. (2012). Exploring The Gender Effect on EFL Learners' Learning Strategies. Theory and Practice in Language Studies, 2(8), 1614-1620.

[10] Alhaysony, M. (2017). Language Learning Strategies Use by Saudi EFL Students: The Effect of Duration of English Language Study and Gender. Theory and Practice in Language Studies, 7(1), 18-28.

[11] Ahour, T. \& Abdi, M. (2015). The Relationship Between EFL Learners' Multiple Intelligences and Vocabulary Learning Strategies Use With A Focus on Gender. Theory and Practice in Language Studies, 5(4), 800-809.

[12] Wu, J. (2014). Characteristics of Chinese Primary School Students' EFL Learning Strategies. Theory and Practice in Language Studies, 4(6), 1266-1272.

[13] Huang, K. M. (2015). Gender Differences in English Learning Beliefs and Learning Strategies Use. Unpublished Master's Thesis, National Pingtung University, Taiwan.

[14] Marzban, A. \& Barati, Z. (2016). on The Relationship Between Critical Thinking Ability, Language Learning Strategies, and Reading Comprehension of Male and Female Intermediate EFL University Students. Theory and Practice in Language Studies, 6(6), 1241-1247.

[15] Huang, H. J. (2017). Gender Difference in Learning Style Preference and Learning Strategies Use. Unpublished Master's Thesis, National Pingtung University, Taiwan.

[16] Hsiung, Y. C. (2011). A Study on Vocabulary Learning Strategies Used by Eighth-Grade Students in Taiwan. Unpublished Master's Thesis, Fu Jen Catholic University.

[17] Chuin, T. K. \& Kaur, S. (2015). Types of Language Learning Strategies Used by Tertiary English Majors. TEFLIN Journal, 26(1), 17-35.

[18] Chen, A. L. (2014).Age Differences in the Use of Language Learning Strategies. English Language Learning, 7(2), 144-151. 
[19] Sepasdar, M. \& Soori, A. (2014). The Impact of Age on Using Language Learning Strategies. international journal of education\& literacy studies, 2(3), 26-31.

Citation: Ching-Ying Lin, Si-Wei Hong. "Language Learning Strategies Using on Vocabulary Learning ". International Journal on Studies in English Language and Literature (IJSELL), vol 6, no. 12, 2018, pp. 31-39. doi: http://dx.doi.org/10.20431/2347-3134.0612004.

Copyright: (C) 2018 Authors. This is an open-access article distributed under the terms of the Creative Commons Attribution License, which permits unrestricted use, distribution, and reproduction in any medium, provided the original author and source are credited. 